\title{
PENGARUH PENAMBAHAN KULIT JERUK BALI (Citrus maxima) TERHADAP KUALITAS MINYAK GORENG YANG MENGALAMI PEMANASAN
}

\author{
Jaka Fadraersada \\ Laboratorium Penelitian dan Pengembangan FARMAKA TROPIS Fakultas Farmasi \\ Universitas Mulawarman, Samarinda, Kalimantan Timur \\ email: jakafadraersada@gmail.com
}

\begin{abstract}
Cooking oil is used to fry foods. The longer and more frequent the cooking oil being used, more its quality is getting lower. The goal of this research is to know if there is an effect of adding grapefruit peels due to the quality of cooking oil that has been used several times. Grapefruit peel contains lycopene which can reduce oxidation process. By adding grapefruit peel, we hope its can reduce the lowering quality. The orientation shows that $3 \%$ grapefruit peel weight/weight is the most efficient concentration to be used. And with $3 \%$ grapefruit peel weight/weight, the results shows a big difference between cooking oil with no grapefruit peel addition and cooking oil with grapefruit peel addition.
\end{abstract}

Keywords: Cooking oil, frying, grapefruit peel, quality of cooking oil

\begin{abstract}
ABSTRAK
Minyak goreng digunakan untuk memasak bahan makanan. Semakin lama dan semakin sering minyak goreng digunakan, kualitasnya akan semakin menurun. Tujuan dari penelitian ini adalah untuk mengetahui efek dari penambahan kulit Jeruk Bali pada kualitas minyak goreng yang mengalami pemanasan berulang. Kulit Jeruk Bali merupakan produk waste (buangan) yang mengandung likopen yang dapat mengurangi proses oksidasi. Dengan menambahkan kulit Jeruk Bali, diharapkan dapat mencegah penurunan kualitas minyak goreng. Dari penelitian didapatkan hasil bahwa 3\% B/B kulit Jeruk Bali merupakan konsentrasi terbaik yang dapat digunakan. Pada studi ini minyak goreng yang diberi tambahan kulit Jeruk Bali dengan konsentrasi 3\% B/B menunjukkan perbedaan yg besar pada beberapa parameter SNI dibandingkan dengan minyak goreng tanpa pemberian kulit Jeruk Bali setelah dipanaskan.
\end{abstract}

Kata Kunci: Kulit Jeruk Bali, minyak goring, pemanasan

\section{PENDAHULUAN}

Makanan merupakan salah satu kebutuhan pokok manusia. Manusia perlu mengolah makanan yang ada supaya bisa dimakan, terlebih lagi bisa dinikmati. Salah satu cara mengolah makanan adalah dengan menggoreng menggunakan minyak goreng. Minyak goreng merupakan penghantar panas, penambah rasa gurih dan penambah nilai kalori bahan pangan. Namun, kenaikan harga kebutuhan pokok akibat kebijaksanaan pemerintah yang menaikkan harga BBM mendorong masyarakat industri dan rumah tangga menggunakan minyak goreng secara berulang kali. Pemakaian kembali minyak goreng bekas pakai beresiko membahayakan kesehatan yang disebabkan kemungkinan kerusakan minyak akibat penyimpanan yang lama dan akibat pemanasan yang berulang. Pada pemanasan minyak, terjadi tiga proses utama yang menyebabkan 
kerusakan minyak yaitu oksidasi, hidrolisis dan polimerisasi.

Jenis-jenis minyak goreng yang beredar di pasaran diantaranya terbuat dari bahan-bahan nabati berupa kelapa, kelapa sawit, jagung, kacang tanah, kedelai dan beberapa campuran minyakminyak tersebut. Minyak nabati yang sudah teroksidasi mengalami penurunan kualitas dan menyebabkan keracunan serta efek negatif lainnya bagi manusia. Laju oksidasi dipengaruhi oleh adanya oksidan dan antioksidan yang menghambat proses oksidasi minyak. Oksidan merupakan senyawa yang dapat menerima elektron dan radikal bebas adalah suatu molekul dengan atom yang pada orbit terluarnya memiliki elektron yang tidak berpasangan. Karena kehilangan pasangan itu, molekul menjadi tidak stabil dan radikal. Agar menjadi stabil, molekul oksigen di orbital terluarnya harus memiliki dua elektron maka ia akan berusaha menjadi stabil dengan cara berkombinasi dengan molekul lain. Bila radikal bebas menyerang lemak tidak jenuh dengan kehadiran oksigen, peroksida-peroksida lemak akan terbentuk dalam rantai yang makin panjang. Selanjutnya akan terjadi kerusakan pada minyak goreng yang ditandai dengan bau dan rasa tengik.

Salah satu cara yang digunakan untuk mencegah kerusakan diatas adalah dengan penambahan antioksidan. Penambahan antioksidan ini lebih baik bila biayanya rendah sehingga bisa dinikmati dan dilakukan oleh semua lapisan masyarakat. Dengan bertujuan agar bisa dilakukan oleh semua lapisan masyarakat, maka dalam percobaan ini digunakan produk yang tidak digunakan, yaitu kulit dari jeruk bali. Di dalam jeruk bali terkandung senyawa likopen dan vitamin $\mathrm{C}$ yang mempunyai aktivitas sebagai antioksidan. (Yanuarta, 2007)

Dengan adanya penambahan antioksidan likopen yang terdapat di dalam kulit jeruk bali pada minyak goreng yang akan digunakan, diharapkan akan mengurangi proses oksidasi sehingga dapat mengurangi jumlah zatzat hasil oksidasi dan penurunan kualitas minyak goreng dapat diminimalkan.

\section{METODE PENELITIAN}

\section{Bahan}

Bahan yang diteliti adalah Minyak goreng ' $\mathrm{X}$ ' pabrik ' $\mathrm{Y}$ '.

\section{Peralatan}

Labu Erlenmeyer, beker glas, cawan poselen, buret (Pyrex), neraca analitik Sartorius tipe 2472, termometer, bunsen, wajan, refraktometer ABBE.

\section{Prosedur Penelitian}

Tahap pertama yang harus dilakukan adalah melakukan uji SNI pada minyak goreng yang digunakan, minyak goreng dibagi menjadi 2, yaitu kontrol (tanpa perlakuan) dan juga perlakuan yaitu dengan penambahan kulit dari jeruk bali. Kemudian dilakukan pemanasan selama 15 menit pada suhu $170-180^{\circ} \mathrm{C}$ berulang hingga 4 kali disertai dengan penambahan kulit dari jeruk bali pada setiap akan dilakukan pemanasan yang dilanjutkan dengan uji SNI. Pada setiap perlakuan dan kontrol dilakukan replikasi sebanyak tiga kali. Dari uji SNI ini dapat diketahui apakah minyak goreng dengan penambahan kulit dari jeruk bali dapat mengurangi penurunan kualitas minyak goreng.

\section{Penentuan Bilangan Iod}

Sebanyak 0,5 gram minyak dilarutkan dengan $15 \mathrm{ml}$ Karbon Tetraklorida di dalam labu Erlenmeyer tertutup. Ke dalam erlenmeyer tersebut ditambahkan $25 \mathrm{ml}$ larutan Wijs dan disimpan selama 2 jam dalam tempat yang gelap. Kemudian ditambahkan 10 $\mathrm{ml}$ KI $30 \%$ dan $50 \mathrm{ml}$ aquades dan erlenmeyer segera ditutup kembali. Dititer dengan Natrium Tiosulfat $0,1 \mathrm{~N}$ dengan indikator Amilum (misalnya diperlukan a ml Natrium Tiosulfat 0,1 N). 
Blanko dikerjakan seperti tersebut diatas (misalnya diperlukan b $\mathrm{ml}$ Natrium Tiosulfat $0,1 \mathrm{~N}$ ).

\section{Penentuan Bilangan Peroksida}

Sebanyak $\pm 5 \mathrm{~g}$ minyak ditimbang dalam erlenmeyer $300 \mathrm{~mL}$ tertutup. Kemudian ditambah dengan $30 \mathrm{ml}$ larutan dari suatu campuran yang terdiri dari $20 \mathrm{ml}$ Asam asetat, $25 \mathrm{ml}$ alkohol 96\% dan $55 \mathrm{ml}$ kloroform. Ditambahkan 1 gram KI yang sebelumnya dilarutkan dengan $5 \mathrm{ml}$ aquades dicampur hingga homogen pada tempat yang gelap selama $1 / 2$ jam. Terakhir ditambahkan $50 \mathrm{ml}$ aquades dan dititer dengan Natrium Tiosulfat $0,002 \mathrm{~N}$ dan sebagai indikator digunakan larutan amilum (misalnya diperlukan a $\mathrm{mL}$ ). Blanko dikerjakan seperti tersebut diatas (misalnya diperlukan $\mathrm{b} \mathrm{mL}$ ).

\section{Penentuan Asam Lemak Bebas}

Sebanyak \pm 10 gram minyak ditimbang dan dimasukkan ke dalam labu Erlenmeyer, ditambah campuran Alkohol 96\% : Petroleum benzen (1:1). Larutan ini dititer dengan Natrium Hidroksida 0,1 $\mathrm{N}$ dan Fenolftalein sebagai indikator (dititer sampai warna merah jambu tidak hilang selama 1 menit).

\section{HASIL DAN PEMBAHASAN}

\section{Penentuan Nilai Parameter SNI Minyak Goreng Tanpa Pemanasan}

Nilai tiap parameter dan rata-rata dari minyak goreng yang digunakan dalam penelitian ini yang belum diberikan perlakuan apapun terlihat pada tabel 1.

Tabel 1. Nilai Parameter SNI Terpilih dari Minyak Goreng Kontrol

\begin{tabular}{cccccc}
\hline Parameter & Replikasi 1 & Replikasi 2 & Replikasi 3 & Rerata & $\begin{array}{c}\text { Nilai } \\
\text { Standar SNI }\end{array}$ \\
\hline Bilangan Iod & 143,91 & 140,71 & 142,71 & 142,44 & $45-46$ \\
Bilangan Peroksida & 0,0436 & 0,04613 & 0,0489 & 0,0462 & Maksimal 2 meq/Kg \\
Asam Lemak Bebas & $0,80 \%$ & $0,80 \%$ & $1,00 \%$ & $0,87 \%$ & Maksimal 0,3\% \\
\hline
\end{tabular}

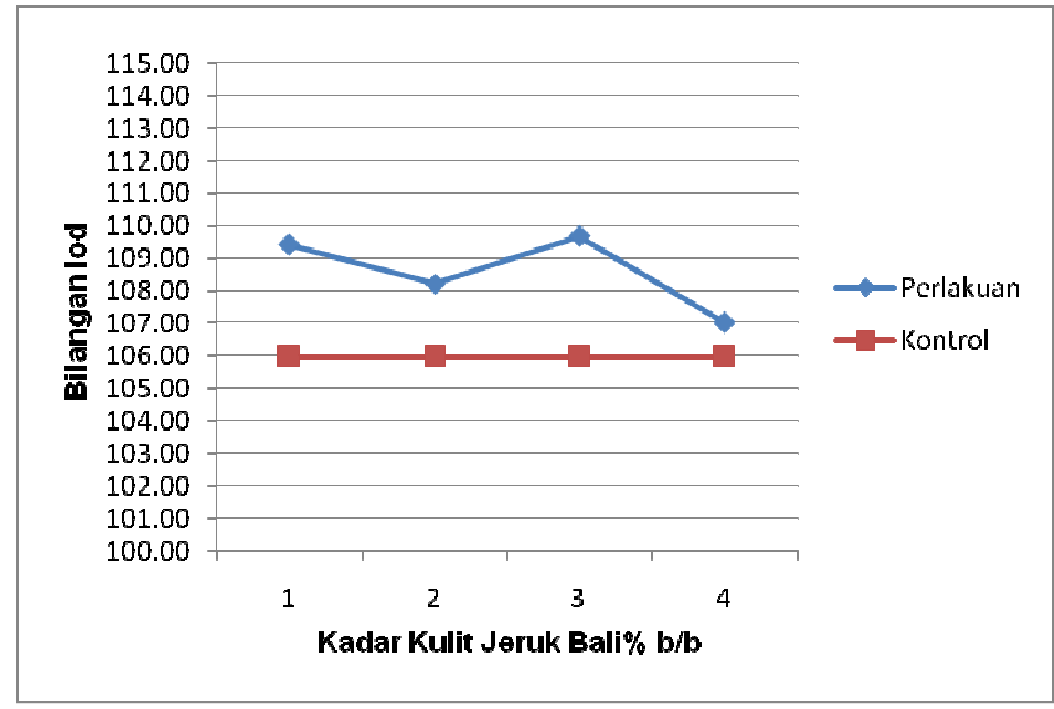

Gambar 1. Grafik Nilai Rerata Data Uji Pengaruh Pemberian Kadar Kulit Jeruk Bali Terhadap Bilangan Iod Minyak Goreng 
Tabel 2. Data Uji Pengaruh Pemberian Kadar Kulit Jeruk Bali Terhadap Bilangan Iod Minyak Goreng

\begin{tabular}{|c|c|c|c|c|c|}
\hline $\begin{array}{c}\text { Kadar } \\
\text { Kulit Jeruk Bali } \\
(\% \text { b/b })\end{array}$ & Replikasi & $\Delta \mathrm{V}$ Na Tio (ml) & Berat Minyak (g) & $\begin{array}{l}\text { Bilangan Iod } \\
\text { (g Iod/100g) }\end{array}$ & Rerata \\
\hline \multirow{3}{*}{1} & 1 & 22,74 & 0,2506 & 111,28 & \multirow{3}{*}{109,42} \\
\hline & 2 & 22,58 & 0,2559 & 108,21 & \\
\hline & 3 & 22,68 & 0,2555 & 108,76 & \\
\hline \multirow{3}{*}{2} & 1 & 22,50 & 0,2533 & 108,93 & \multirow{3}{*}{108,22} \\
\hline & 2 & 22,58 & 0,2588 & 106,70 & \\
\hline & 3 & 22,46 & 0,2526 & 109,04 & \\
\hline \multirow{3}{*}{3} & 1 & 22,78 & 0,2570 & 108,70 & \multirow{3}{*}{109,67} \\
\hline & 2 & 22,64 & 0,2521 & 110,13 & \\
\hline & 3 & 22,72 & 0,2529 & 110,17 & \\
\hline \multirow{3}{*}{4} & 1 & 22,40 & 0,2581 & 106,43 & \multirow{3}{*}{107} \\
\hline & 2 & 22,34 & 0,2551 & 107,40 & \\
\hline & 3 & 22,24 & 0,2545 & 107,17 & \\
\hline \multirow{3}{*}{ Kontrol } & 1 & 21,68 & 0,2518 & 105,59 & \multirow{3}{*}{105,96} \\
\hline & 2 & 21,82 & 0,2624 & 106,02 & \\
\hline & 3 & 21,76 & 0,2511 & 106,27 & \\
\hline
\end{tabular}

Tabel 3. Data Uji Pengaruh Pemberian Kadar Kulit Jeruk Bali Terhadap Bilangan Peroksida Minyak Goreng

\begin{tabular}{|c|c|c|c|c|c|}
\hline $\begin{array}{c}\text { Kadar } \\
\text { Kulit Jeruk } \\
\text { Bali } \\
(\% \text { b/b })\end{array}$ & Replikasi & $\begin{array}{c}\Delta \mathrm{V} \text { Na Tio } \\
(\mathrm{ml})\end{array}$ & $\begin{array}{c}\text { Berat Minyak } \\
(\mathrm{g})\end{array}$ & $\begin{array}{l}\text { Bilangan } \\
\text { Peroksida } \\
(\mathrm{meq} / \mathrm{Kg})\end{array}$ & $\begin{array}{c}\text { Rerata } \\
(\mathrm{meq} / \mathrm{Kg})\end{array}$ \\
\hline \multirow{3}{*}{1} & 1 & 21,70 & 2,5009 & 0,1342 & \multirow{3}{*}{0,1348} \\
\hline & 2 & 22,75 & 2,5133 & 0,1400 & \\
\hline & 3 & 21,20 & 2,5185 & 0,1302 & \\
\hline \multirow{3}{*}{2} & 1 & 20,70 & 2,5077 & 0,1276 & \multirow{3}{*}{0,1314} \\
\hline & 2 & 21,95 & 2,5192 & 0,1347 & \\
\hline & 3 & 21,35 & 2,5030 & 0,1319 & \\
\hline \multirow{3}{*}{3} & 1 & 19,65 & 2,5044 & 0,1213 & \multirow{3}{*}{0,1254} \\
\hline & 2 & 20,90 & 2,5124 & 0,1286 & \\
\hline & 3 & 20,45 & 2,5040 & 0,1263 & \\
\hline \multirow{3}{*}{4} & 1 & 20,30 & 2,5043 & 0,1253 & \multirow{3}{*}{0,1264} \\
\hline & 2 & 21,05 & 2,5003 & 0,1302 & \\
\hline & 3 & 20,15 & 2,5195 & 0,1237 & \\
\hline \multirow{3}{*}{ Kontrol } & 1 & 22,15 & 2,5090 & 0,1365 & \multirow{3}{*}{0,1454} \\
\hline & 2 & 23,25 & 2,5125 & 0,1431 & \\
\hline & 3 & 25,40 & 2,5089 & 0,1565 & \\
\hline
\end{tabular}




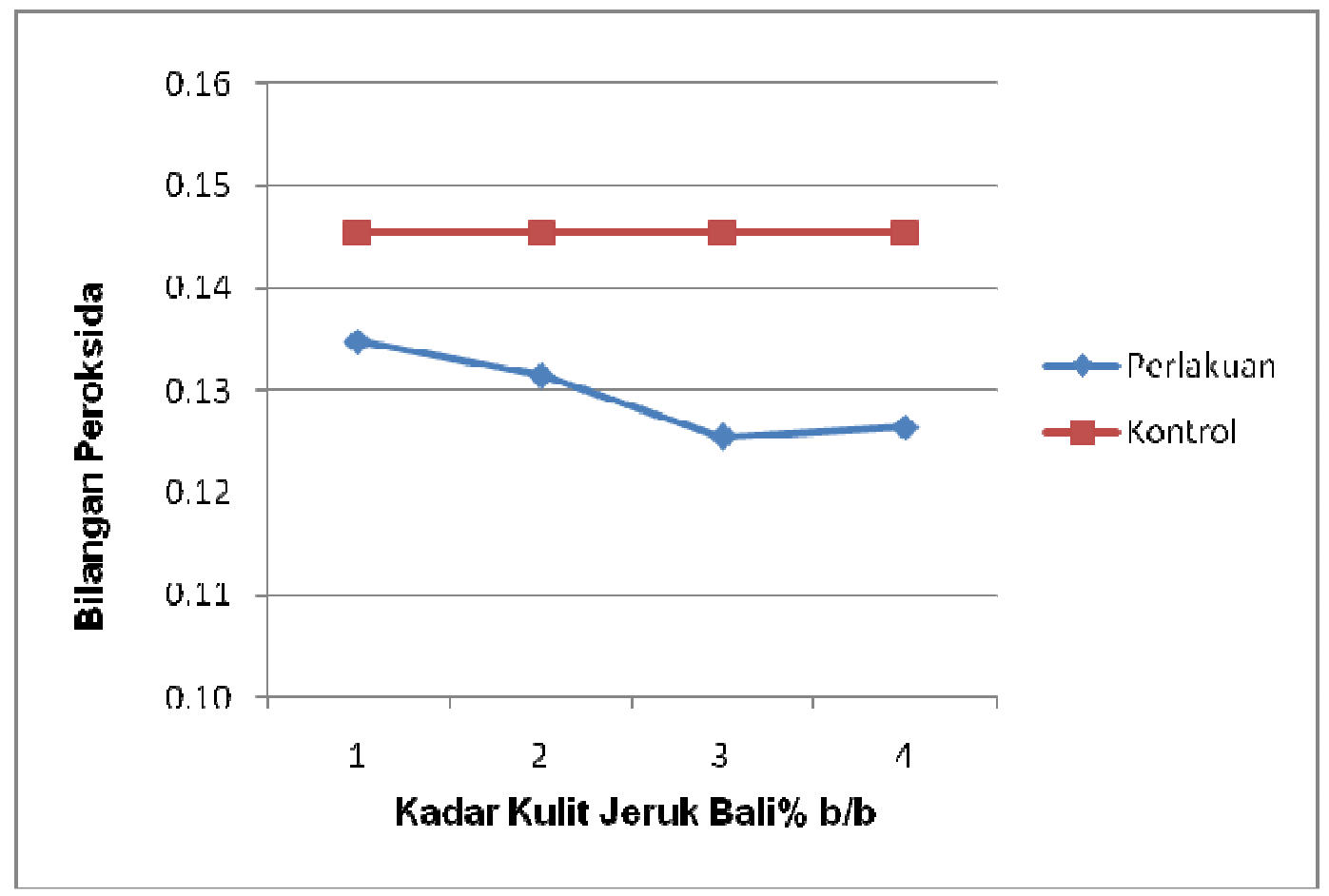

Gambar 2. Grafik Nilai Rerata Data Uji Pengaruh Pemberian Kadar Kulit Jeruk Bali Terhadap Bilangan Peroksida Minyak Goreng

Tabel 4. Data Uji Pengaruh Pemberian Kadar Kulit Jeruk Bali Terhadap Kadar Asam Lemak Bebas Minyak Goreng

\begin{tabular}{|c|c|c|c|c|c|}
\hline $\begin{array}{c}\text { Kadar Kulit } \\
\text { Jeruk Bali } \\
(\% \mathrm{~b} / \mathrm{b})\end{array}$ & Replikasi & $\begin{array}{l}\mathrm{V} \mathrm{NaOH} \\
\quad(\mathrm{ml})\end{array}$ & $\begin{array}{l}\text { Berat } \\
\text { minyak } \\
(\mathrm{g})\end{array}$ & $\begin{array}{c}\text { Kadar Asam Lemak } \\
\text { Bebas }(\%)\end{array}$ & $\begin{array}{c}\text { Rerata } \\
(\%)\end{array}$ \\
\hline \multirow{3}{*}{1} & 1 & 0,35 & 4,9992 & 1,41 & \multirow{3}{*}{1,46} \\
\hline & 2 & 0,38 & 5,0186 & 1,52 & \\
\hline & 3 & 0,36 & 5,0142 & 1,44 & \\
\hline \multirow{3}{*}{2} & 1 & 0,37 & 5,0050 & 1,49 & \multirow{3}{*}{1,45} \\
\hline & 2 & 0,35 & 4,9962 & 1,41 & \\
\hline & 3 & 0,36 & 5,0026 & 1,44 & \\
\hline \multirow{3}{*}{3} & 1 & 0,33 & 5,0026 & 1,33 & \multirow{3}{*}{1,38} \\
\hline & 2 & 0,34 & 4,9970 & 1,37 & \\
\hline & 3 & 0,36 & 5,0037 & 1,44 & \\
\hline \multirow{3}{*}{4} & 1 & 0,35 & 5,0094 & 1,40 & \multirow{3}{*}{1,42} \\
\hline & 2 & 0,37 & 5,0080 & 1,48 & \\
\hline & 3 & 0,34 & 5,0037 & 1,37 & \\
\hline \multirow{3}{*}{ Kontrol } & 1 & 0,40 & 5,0027 & 1,61 & \multirow{3}{*}{1,49} \\
\hline & 2 & 0,35 & 5,0043 & 1,41 & \\
\hline & 3 & 0,36 & 5,0108 & 1,44 & \\
\hline
\end{tabular}




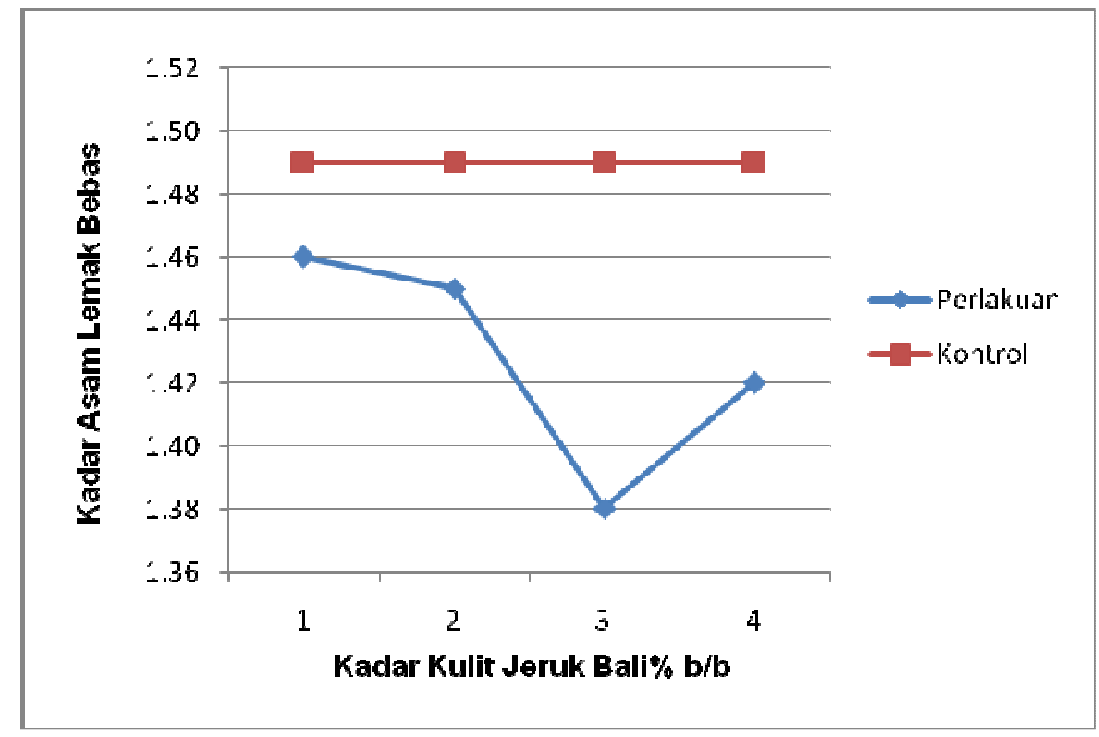

Gambar 3. Grafik Nilai Rerata Data Uji Pengaruh Pemberian Kadar Kulit Jeruk Bali Terhadap Kadar Asam Lemak Bebas Minyak Goreng

Tabel 5. Nilai t Hitung Kelompok Perlakuan Terhadap Kontrol pada Uji Pengaruh Pemberian Kadar Kulit Jeruk Bali Terhadap Minyak Goreng

\begin{tabular}{cccc}
\hline Kadar & \multicolumn{2}{c}{ Nilai t hitung Kelompok Perlakuan Terhadap Kontrol } \\
\cline { 2 - 4 } $\begin{array}{c}\text { Kulit Jeruk Bali } \\
(\% \text { b/b) }\end{array}$ & \multirow{2}{*}{ Bilangan Iod } & Bilangan & Kadar \\
& Peroksida & Asam Lemak Bebas \\
\hline 1 & $\mathbf{3 , 0 2 5 2}$ & 0,2022 & $\mathbf{4 , 6 5 1 7}$ \\
2 & $\mathbf{4 , 0 1 4 0}$ & 0,2922 & $\mathbf{7 , 3 5 2 4}$ \\
3 & $\mathbf{1 1 , 0 4 4 5}$ & 0,4138 & $\mathbf{1 7 , 0 9 5 8}$ \\
4 & $\mathbf{6 , 8 1 5 9}$ & 0,4018 & $\mathbf{1 0 , 8 9 0 3}$ \\
\hline
\end{tabular}

\section{Bilangan Iod}

Dari tabel 2 dan gambar 1 dapat dilihat nilai rerata bilangan iod perlakuan lebih tinggi daripada kontrol, sehingga dapat disimpulkan bahwa penambahan kulit jeruk bali sebesar 1-4 \% dapat mengurangi pemutusan ikatan rangkap yang dapat menyebabkan penurunan nilai bilangan iod pada minyak goreng yang mengalami pemanasan.

\section{Bilangan Peroksida}

Dari tabel 3 dan gambar 2 dapat dilihat nilai rerata bilangan peroksida perlakuan lebih rendah daripada kontrol, sehingga dapat disimpulkan bahwa penambahan kulit jeruk bali sebesar 1-4
$\%$ dapat mengurangi pembentukan peroksida yang menyebabkan peningkatan nilai bilangan peroksida pada minyak goreng yang mengalami pemanasan.

\section{Kadar Asam Lemak Bebas}

Dari tabel 4 dan gambar 3 dapat dilihat nilai rerata kadar asam lemak bebas perlakuan lebih rendah daripada kontrol, sehingga dapat disimpulkan bahwa penambahan kulit jeruk bali sebesar 1-4 \% dapat mengurangi pembentukan asam lemak yang menyebabkan peningkatan nilai kadar asam lemak bebas pada minyak goreng yang mengalami pemanasan. 


\section{Hasil Analisis Statistika Orientasi Kadar dengan Uji t}

Adapun nilai t tabel untuk uji onetailed dengan $\alpha=0,05$ adalah sebesar 2,132 . Nilai t hitung yang lebih besar dari $\mathrm{t}$ tabel dicetak tebal (tabel 5).

Hasil yang didapat menunjukkan bahwa nilai bilangan iod dan kadar asam lemak bebas semua kelompok perlakuan dengan penambahan kulit jeruk bali pada semua kadar menunjukkan perbedaan yang bermakna terhadap kontrol. Kadar kulit jeruk bali $3 \%$ b/b merupakan kadar terpilih.

\section{KESIMPULAN}

Penambahan kulit dari jeruk bali (Citrus maxima) sebesar 3\% b/b mampu mengurangi penurunan kualitas minyak goreng yang dipanaskan, terutama pada bilangan iod dan kadar asam lemak bebas.

\section{UCAPAN TERIMA KASIH}

Disampaikan kepada Dr. Laode Rijai, M.Si., Drs. yang mengizinkan melakukan penelitian di Laboratorium Penelitian Farmaka Tropis Fakultas Farmasi Universitas Mulawarman, dan kepada Laboran Laboratorium Penelitian Farmaka Tropis Fakultas Farmasi Universitas Mulawarman atas bantuannya dalam menyelesaikan penelitian ini.

\section{DAFTAR PUSTAKA}

1. Raharjo, S. 2008. Melindungi Kerusakan Oksidasi pada Minyak Selama Penggorengan dengan Antioksidan. Foodreview Indonesia Vol.III.No.4.April 2008.

2. Surjadibroto, W. 2003. Bahaya radikal bebas dalam makanan kita. Majalah GizMindo;2(6):11-2.

3. Warner, F.G. 2002. Chemistry of Frying Oils. U.S. Departemen of Agriculture, Peoria, Illinois dalam Akoh C.C., Min B.D., ed. 2002. Food Lipids: Chemistry, Nutrition, and Biotechnology. $\quad 2^{\text {nd }}$ Ed. Marcell Dekker. Inc. New York. 